\title{
Trends in opioid use in commercially insured and Medicare Advantage populations in 2007-16: retrospective cohort study
}

\author{
Molly Moore Jeffery, ${ }^{1}$ W Michael Hooten ${ }^{2}$ Henry J Henk, ${ }^{3}$ M Fernanda Bellolio, ${ }^{4}$ Erik P Hess, ${ }^{5}$ \\ Ellen Meara, ${ }^{6,7}$ Joseph S Ross, ${ }^{8}$ Nilay D Shah ${ }^{1,3}$
}

${ }^{1}$ Mayo Clinic Robert D and

Patricia E Kern Center for the

Science of Health Care Delivery,

Division of Health Care Policy

Research, Department of Health

Sciences Research, Mayo Clinic,

Rochester, MN 55905, USA

${ }^{2}$ Department of Anesthesiology,

Mayo Clinic College of Medicine,

Rochester, MN, USA

${ }^{3}$ OptumLabs, Eden Prairie, MN, USA

${ }^{4}$ Department of Emergency

Medicine, Mayo Clinic

Rochester, MN, USA

${ }^{5}$ Department of Emergency

Medicine, University of Alabama

at Birmingham School of

Medicine, Birmingham, AL, USA

${ }^{6}$ Dartmouth Institute for Health

Policy and Clinical Practice,

Dartmouth College, Lebanon,

$\mathrm{NH}$, USA

${ }^{7}$ National Bureau of Economic

Research, Cambridge, MA, USA

${ }^{8}$ Department of Internal

Medicine, Yale University School

of Medicine, New Haven, CT,

USA

Correspondence to:

M M Jeffery

jeffery.molly@mayo.edu

(or @mollyjeffery on Twitter)

Additional material is published online only. To view please visit

the journal online.

Cite this as: BMJ 2018;362:k2833

http://dx.doi.org/10.1136/bmj.k2833

Accepted: 12 June 2018

\section{ABSTRACT}

OBJECTIVE

To describe trends in the rate and daily dose of opioids used among commercial and Medicare Advantage beneficiaries from 2007 to 2016.

\section{DESIGN}

Retrospective cohort study of administrative claims data.

\section{SETTING}

National database of medical and pharmacy claims for commercially insured and Medicare Advantage beneficiaries in the United States.

\section{PARTICIPANTS}

48 million individuals with any period of insurance coverage between 1 January 2007 and 31 December 2016, including commercial beneficiaries, Medicare Advantage beneficiaries aged 65 years and over, and Medicare Advantage beneficiaries under age 65 years (eligible owing to permanent disability).

\section{MAIN ENDPOINTS}

Proportion of beneficiaries with any opioid

prescription per quarter, average daily dose in milligram morphine equivalents (MME), and proportion of opioid use episodes that represented long term use.

\section{RESULTS}

Across all years of the study, annual opioid use prevalence was $14 \%$ for commercial beneficiaries, $26 \%$ for aged Medicare beneficiaries, and $52 \%$ for disabled Medicare beneficiaries. In the commercial beneficiary group, quarterly prevalence of opioid use changed little, starting and ending the study period at $6 \%$; the average daily dose of $17 \mathrm{MME}$ remained unchanged since 2011 . For aged Medicare beneficiaries, quarterly use prevalence was also relatively stable, ranging from $11 \%$ at the beginning of the study period to $14 \%$ at the end. Disabled Medicare beneficiaries had the highest rates of opioid use, the highest rate of long term use, and the largest average daily doses. In this group, both quarterly

\section{WHAT IS ALREADY KNOWN ON THIS TOPIC}

Population data suggests that opioid use in the United States has fallen since its peak in 2012

Rates of opioid use and daily doses have not been well characterized for some patient populations

\section{WHAT THIS STUDY ADDS}

Opioid use and average daily dose measured at the individual level have not substantially fallen from their peaks, despite increased attention to opioid abuse and awareness of their risks use rates (39\%) and average daily dose (56 MME) were higher at the end of 2016 than the low points observed in 2007 for each endpoint (26\% prevalence and $53 \mathrm{MME}$ ).

\section{CONCLUSIONS}

Opioid use rates were high during the study period of 2007-16, with the highest rates in disabled Medicare beneficiaries versus aged Medicare beneficiaries and commercial beneficiaries. Opioid use and average daily dose have not substantially declined from their peaks, despite increased attention to opioid abuse and awareness of their risks.

\section{Introduction}

The United States has the highest rate of opioid use in the world, consuming $88 \%$ more prescription opioids per capita than second ranked Germany and seven times more than the United Kingdom. ${ }^{1}$ An average of 40 people die in the US every day from a prescription opioid overdose-a fourfold increase since $1999 .^{2}$ Opioid use has been declared a public health emergency, with legally prescribed drugs contributing to substantial morbidity and mortality from addiction and overdose. . $^{3-5}$

Studies reporting on population level opioid use have had some key limitations. Sales and supply data track nearly all legally distributed opioids, but these data do not link to patient demographics. ${ }^{67}$ The National Survey on Drug Use and Health includes patient information, but is limited to patient self report of opioid use and excludes children under age 12 years. ${ }^{8}$ The most commonly used source of healthcare claims data-Medicare fee-for-service data-provides excellent patient level data, but is limited to Medicare beneficiaries. $^{910}$

As a result, current knowledge about opioid use in the US is largely derived from studies of a single state or healthcare system, ${ }^{11-14}$ or market level information that limits detailed examination of prevalence, patient level use, or subgroup analyses. ${ }^{6} 15$ Market level data from prescriptionfills cannot be used to determine the proportion of people who use opioids in a given year unless prescriptions filled by the same person can be identified. Without a unique person level identifier, only the rate of prescriptions per capita can be calculated, rather than the proportion of people using opioids in a given year; the two estimates can diverge if a small number of people fill a large proportion of prescriptions. As a result, relatively little is known about person level opioid use in large national samples outside of Medicare fee-for-service beneficiaries. There are few sources of claims data for Medicare Advantage beneficiaries, who are believed to be healthier than 
fee-for-service beneficiaries, ${ }^{16}$ but have not been studied in depth; there are also few datasets that cover a geographically diverse group of commercially insured beneficiaries. Both of these populations are included in the OptumLabs Data Warehouse.

Accordingly, our objective was to describe the prevalence of use, dose, and duration of prescription opioids used in a large population, including both commercially insured and Medicare Advantage beneficiaries (31\% of all Medicare beneficiaries ${ }^{17}$ ), from 2007 to 2016. Using a national claims database, we aimed to explore the prevalence of opioid use and trends over the study period in subpopulations defined by insurance type (commercial, aged Medicare, and disabled Medicare) and by age. The primary goal of this paper was to estimate the change in opioid use across age and coverage types since 2007, in the face of increasing emphasis on improving prescribing patterns and preventing adverse outcomes. As a secondary goal, we also assessed the extent of concentration of opioid use in long term use episodes and among the beneficiaries with the greatest use of opioids.

\section{Methods}

\section{Participants}

We drew pharmacy claims from the OptumLabs Data Warehouse (OLDW), a database of claims for healthcare services, insurance enrollment, and demographic information. The OLDW includes both commercially insured and Medicare Advantage beneficiaries, including age eligible beneficiaries (age $\geq 65$ years) and individuals eligible for Medicare before age 65 years owing to permanent disability. Our study included all beneficiaries with medical and pharmacy coverage for any period of time between 1 January 2007 and 31 December 2016.

The OLDW includes $20 \%$ of the commercially insured population in the US and $24 \%$ of the Medicare Advantage population. The distributions of age, sex, and race or ethnicity in the database are similar to the US commercial and Medicare Advantage populations. People from all census divisions are represented in the OLDW, with a higher proportion of OLDW beneficiaries in the West North Central and South Atlantic census divisions than in the entire insured population. We report results adjusted for patient characteristics, including census division, to mitigate the effect of the differences. Appendix 1 shows a comparison of the OLDW population with the US insured population.

This study was determined to be exempt from review by the Mayo Clinic Institutional Review Board. A statement on data access, cleaning, and sharing is available in appendix 2 .

\section{Variables}

All opioids available during any part of the study period were identified. To allow direct comparison of doses across different drugs and formulations, we used conversion factors from the Centers for Disease Control and Prevention to translate the milligram of each drug into milligram morphine equivalents (MME). ${ }^{18}$
We amended that list of conversion factors to convert propoxyphene napsylate at a different rate from propoxyphene hydrochloride, taking into account the differences in molecular weight between the two salts. ${ }^{19}$ Appendix 3 provides details of opioids used and conversion factors.

For all opioid prescriptions filled during the study period, we linked the prescribed dose in MME and the total days supplied to an individual beneficiary. Prescriptions written for the same active ingredient and filled on the same day were consolidated and treated as one prescription, using the maximum count days' supply across the fills. We calculated the average daily prescribed dose for each drug fill as the total MME dispensed divided by the number of person days of insurance enrollment in that period (that is, quarter). ${ }^{20}$ Opioid drug fills that were calculated as having a dose of over 1000 MME per drug per day were excluded as potential recording errors ( $n=40674$ fills; $0.05 \%$ of consolidated fills for beneficiaries eligible for enrollment). Appendix 4 shows the cohort flowcharts of drug fills and beneficiaries.

Opioid prescriptions were allocated to a year and quarter, on the basis of the fill date and days supplied. For example, a 30 day prescription filled on 31 December 2008 would have been allocated as one day in quarter 4 of 2008 and 29 days in quarter 1 of 2009. Opioid use was measured quarterly as a binary indicator of use, using pharmacy claims as a proxy for opioid fills.

We constructed episodes of opioid use by grouping all contiguous opioid fills by a single beneficiary. An episode of opioid use was defined as the time from the fill date of the first prescription in the episode to the last day of the final prescription. Each episode ended when 30 days lapsed without an opioid fill after the last day of the last prescription in the episode. An alternative episode definition allowing 40 days to lapse between the end of one prescription and the beginning of the next did not substantially change the distribution of chronic and non-chronic episodes. Using criteria from Von Korff and colleagues, ${ }^{20}$ we categorized episodes of opioid use as long term if the prescription dates spanned at least 90 days and included either at least 120 days' supply, or at least 10 fills.

A proportion of episodes were left or right censored by the study or insurance coverage periods. Because the length of episodes starting before beneficiaries were observed cannot be determined, the analysis of opioid use episodes was limited to those episodes that started 30 or more days after the later of the beginning of the study period or the beginning of the beneficiary's coverage period. To account for right censoring, the analysis of episodes of opioid use was limited to beneficiaries who had at least 365 days of enrollment after the beginning of the episode. Average daily observed dose during an episode of opioid use was calculated as the total MME filled during that episode divided by the number of days in the episode.

The study design allowed enrollees to enter and exit the cohort multiple times and did not require 
enrollees to be covered for a complete calendar quarter or year. Therefore, the denominator was measured in person days or person quarters of insurance coverage. All analyses were stratified by beneficiary category including commercially insured, aged Medicare, and disabled Medicare (beneficiaries with Medicare coverage who were under age 65 years). Box 1 gives further detail on insurance categories.

Beneficiary sex, age, census division of residence, race or ethnicity, coverage type (commercial, aged Medicare, disabled Medicare), and start year of coverage were recorded. Age groups were presented in categories (0-18, 19-34, 35-44, 45-54, 55-64, 65-74, $75+$ years, unknown age).

\section{Statistical methods}

Descriptive statistics are reported as annual averages over the study period. Standard errors for descriptive statistics were clustered by beneficiary ID to account for repeated observations of the same beneficiaries. Quarters of follow-up time per beneficiary are reported (that is, length of insurance coverage).

Endpoints were defined at the person quarter level. We used logistic regression to model the proportion of the population using opioids each quarter. The

\section{Box 1: Types of health insurance in the US}

The US is unusual in the developed world for its patchwork of health insurance coverage.

\section{Commercial insurance (about $49 \%$ of total US population)}

The majority of non-elderly people in the US are covered by commercial insurance, often through their employer or a family member's employer. This coverage is purchased for the group of employees and their families from a commercial insurer. Some employers self insure, but use commercial insurers to administrate their plans, including processing claims and making payments to providers.

Commercial insurers often sell individual policies through insurance brokers or on statewide insurance marketplaces.

All these types of commercial insurance are represented in the OptumLabs Data Warehouse (OLDW).

\section{Medicare/Medicare Advantage ( $14 \%$ of population)}

Two populations are able to access Medicare coverage, a government insurance program. Most US citizens aged 65 years and older are eligible for Medicare owing to age; others are eligible owing to permanent disability, including end stage renal disease and a few other conditions.

Medicare provides hospital insurance (Medicare part A) to all beneficiaries. Beneficiaries may also choose to purchase medical insurance for outpatient services (Medicare part B) and prescription drug coverage (Medicare part D).

Rather than receiving their coverage from the government run plans (known as fee-forservice Medicare), beneficiaries may choose to purchase a plan administered by a commercial insurer known as Medicare Advantage or Medicare part C. These plans provide the services of Medicare parts A, B, and D. Currently, about $30 \%$ of Medicare beneficiaries opt for Medicare Advantage.

The OLDW includes Medicare Advantage beneficiaries.

\section{Other insurances types}

The OLDW does not include a few key insured populations: fee-for-service Medicare (described above), Medicaid (provided by states to generally low income populations, with a special emphasis on pregnant women and children; $19 \%$ of the population), Veterans Administration (for veterans of the armed services), or CHAMPUS (for current members of the armed services and their families; along with Veterans

Administration, about $2 \%$ of the population). average MME per person day by quarter was modelled by a generalized linear model with negative binomial family and log link. The dependent variable was the total MME per person in the quarter, with an exposure variable representing the number of days of insurance coverage for each person included to standardize daily MME. For both analyses, clustered standard errors were used to account for repeated observations of the same beneficiaries. Additional detail about the standard error calculations are included in appendix 5 . With a sample size of nearly 50 million people, statistical significance becomes much less important than clinical significance. We do not report confidence intervals in the text, but they are provided in tables. All analyses were performed in StataMP version $15 .^{21}$

\section{Patient involvement}

No patients were involved in setting the research question or the outcome measures, nor were they involved in developing plans for design or implementation of the study. No patients were asked to advise on interpretation or writing up of results. We will engage patients in the dissemination of the research through blog posts and press releases incorporating the views of people taking opioids chronically, who have a critical stake in the interpretation of research on opioid use.

\section{Results}

Forty eight million unique beneficiaries were observed over the study period, contributing 471 million person quarters of follow-up. Table 1 presents sample characteristics. Appendix 6 presents information on comorbidities in the study population.

\section{Opioid use prevalence}

\section{Population differences in annual opioid} use prevalence

Disabled Medicare beneficiaries were much more likely to use opioids than other beneficiaries (table 2). Averaged across the entire study period, 51.5\% of disabled Medicare beneficiaries used opioids per year ( $n=1128088)$, compared with $14.3 \%(n=18721915)$ of commercial beneficiaries and 25.7\% $(n=3847$ 676) of aged Medicare beneficiaries.

\section{Adjusted time trends in opioid use prevalence by population}

The three groups of beneficiaries experienced different time trends and levels of adjusted opioid use over the study period (fig 1A); complete regression results are available in appendix 7 and predictive margins used to create figure 1 and figure 2 are available in appendix 8. The commercial population's quarterly opioid use prevalence remained relatively steady, with about $7 \%$ using opioids per quarter from quarter 3 of 2007 to quarter 4 of 2014 , when it decreased to $6 \%$ and remained unchanged through the end of the study.

Quarterly opioid use prevalence for the aged Medicare population increased from $12 \%$ at the start 


\begin{tabular}{|c|c|c|c|}
\hline \multirow[b]{2}{*}{ Measure } & \multicolumn{3}{|l|}{ Beneficiaries } \\
\hline & Commercial & Aged Medicare & Disabled Medicare \\
\hline Unique individuals & 42548938 & 4668700 & 825599 \\
\hline Proportion (\%) of sample & 88.6 & 9.7 & 1.7 \\
\hline Total No of person quarters & 430668074 & 55723158 & 7757456 \\
\hline $\begin{array}{l}\text { Median (interquartile range) No of quarters of } \\
\text { follow-up per beneficiary }\end{array}$ & $7(3-14)$ & $9(4-16)$ & $6(4-13)$ \\
\hline No of person years (denominator for demographics) & 130601520 & 14985892 & 2192282 \\
\hline Female sex (years; \%, No; 95\% Cl) & $49.7(n=64910801 ; 49.7$ to 49.7$)$ & $57.8(n=8662208 ; 57.7$ to 57.9$)$ & $52.4(n=1148649 ; 52.3$ to 52.5$)$ \\
\hline \multicolumn{4}{|l|}{ Race/ethnicity (years; \%, No; $95 \%$ Cl) } \\
\hline White & $66.9(n=87370394 ; 66.9$ to 66.9$)$ & $70.1(n=10501174 ; 70.0$ to 70.1$)$ & $60.7(n=1330628 ; 60.6$ to 60.8$)$ \\
\hline Black & $9.7(n=12712439 ; 9.7$ to 9.7$)$ & $11.6(n=1734536 ; 11.5$ to 11.6$)$ & $19.5(n=427939 ; 19.4$ to 19.6$)$ \\
\hline Hispanic & $11.0(n=14353974 ; 11.0$ to 11.0$)$ & $6.8(n=1019250 ; 6.8$ to 6.8$)$ & $8.5(n=185915 ; 8.4$ to 8.6$)$ \\
\hline Asian & $4.8(n=6236991 ; 4.8$ to 4.8$)$ & $2.9(\mathrm{n}=430705 ; 2.9$ to 2.9$)$ & $1.6(n=34301 ; 1.5$ to 1.6$)$ \\
\hline Unknown & $7.6(n=9927722 ; 7.6$ to 7.6$)$ & $8.7(n=1300227 ; 8.6$ to 8.7$)$ & $9.8(n=213769 ; 9.7$ to 9.8$)$ \\
\hline \multicolumn{4}{|l|}{ Age category (years; \%, No; 95\% Cl) } \\
\hline $0-18$ & $24.7(n=32206808 ; 24.6$ to 24.7$)$ & - & $0.0(\mathrm{n}=462 ; 0.0$ to 0.0$)$ \\
\hline $19-34$ & $26.3(n=34287890 ; 26.2$ to 26.3$)$ & - & $3.4(n=195331 ; 3.4$ to 3.5$)$ \\
\hline $35-44$ & $17.4(n=22672082 ; 17.3$ to 17.4$)$ & - & $8.9(n=195331 ; 8.8$ to 9.0$)$ \\
\hline $45-54$ & $17.2(n=22456173 ; 17.2$ to 17.2$)$ & - & $27.0(n=591836 ; 26.9$ to 27.1$)$ \\
\hline $55-64$ & $12.6(n=16472901 ; 12.6$ to 12.6$)$ & - & $60.6(n=1329155 ; 60.5$ to 60.8$)$ \\
\hline $65-74$ & $1.8(n=2341857 ; 1.8$ to 1.8$)$ & $55.1(n=8260518 ; 55.1$ to 55.2$)$ & - \\
\hline $75+$ & $0.1(n=163067 ; 0.1$ to 0.1$)$ & $44.9(n=6725250 ; 44.8$ to 44.9$)$ & - \\
\hline \multicolumn{4}{|l|}{ Census division (\%, No; $95 \% \mathrm{Cl}$ ) } \\
\hline New England & $3.0(n=3890758 ; 3.0$ to 3.0$)$ & $7.7(n=1149985 ; 7.6$ to 7.7$)$ & $5.1(n=112224 ; 5.1$ to 5.2$)$ \\
\hline Mid-Atlantic & $6.8(n=8918835 ; 6.8$ to 6.8$)$ & $10.8(n=1624531 ; 10.8$ to 10.9$)$ & $9.8(n=214610 ; 9.7$ to 9.9$)$ \\
\hline East North Central & $15.3(n=19956075 ; 15.3$ to 15.3$)$ & $17.8(n=2664289 ; 17.7$ to 17.8$)$ & $15.1(n=330073 ; 15.0$ to 15.2$)$ \\
\hline West North Central & $10.7(n=13920342 ; 10.6$ to 10.7$)$ & $14.0(n=2096046 ; 13.9$ to 14.0$)$ & $8.8(n=193544 ; 8.8$ to 8.9$)$ \\
\hline South Atlantic & $25.6(n=33406717 ; 25.6$ to 25.6$)$ & $30.9(n=4629838 ; 30.8$ to 30.9$)$ & $35.3(n=774565 ; 35.2$ to 35.5$)$ \\
\hline East South Central & $4.0(n=5252276 ; 4.0$ to 4.0$)$ & $4.5(n=681066 ; 4.5$ to 4.6$)$ & $8.9(n=194736 ; 8.8$ to 9.0$)$ \\
\hline West South Central & $16.4(n=21384827 ; 16.4$ to 16.4$)$ & $4.0(n=593253 ; 3.9$ to 4.0$)$ & $5.6(n=122794 ; 5.6$ to 5.7$)$ \\
\hline Mountain & $9.4(n=12315881 ; 9.4$ to 9.4$)$ & $5.8(n=871402 ; 5.8$ to 5.8$)$ & $6.4(n=140825 ; 6.4$ to 6.5$)$ \\
\hline Pacific & $8.1(n=10592587 ; 8.1$ to 8.1$)$ & $4.4(n=662153 ; 4.4$ to 4.4$)$ & $4.9(n=106555 ; 4.8$ to 4.9$)$ \\
\hline Unknown/other & $0.7(n=963222 ; 0.7$ to 0.7$)$ & $0.1(n=13329 ; 0.1$ to 0.1$)$ & $0.1(n=2356 ; 0.1$ to 0.1$)$ \\
\hline
\end{tabular}

of the study to quarter 4 of 2010 when it increased to $15 \%$. The prevalence remained between $14 \%$ and $15 \%$ until the end of the study period. Disabled Medicare beneficiaries had a greater change in opioid use over the study period. The proportion using opioids increased from $26 \%$ in quarter 1 of 2007 to a peak level of $41 \%$. This 58\% increase persisted through 2012 and 2013. By the end of 2016, opioid use in this group fell to $39 \%$.

\section{Average dose of opioid prescribed daily, per quarter Average daily opioid dose}

Across the study period, the disabled Medicare population had the highest average daily opioid dose per quarter (that is, total MME dispensed per quarter divided by the number of enrolled days). We found that the disabled Medicare population used 63 MME per person per day compared with $17 \mathrm{MME}$ for commercial beneficiaries and 20 MME for aged Medicare beneficiaries (table 2).

Adjusted time trends in average daily opioid dose Time trends in the average daily dose during the quarter varied across beneficiary groups (fig 1B). In the commercial population, the average daily dose did not change after 2011 (17 MME). The average daily dose increased $16 \%$ in aged Medicare beneficiaries

\section{Table 2 | Summary of opioid use in study population, 2007-16}

\section{Beneficiaries}

\section{Opioid use}

Annual use prevalence (\%; No; $95 \% \mathrm{Cl})^{*}$

Quarterly use prevalence (\%; No; $95 \% \mathrm{Cl}) \dagger$

Average daily dose for people using in quarter (MME; 95\% Cl)‡

Opioid prescriptions per person year* $(\mathrm{No} ; 95 \% \mathrm{Cl})$

Supply of opioids per person year (MME; $95 \%$ Cl)*

Supply of opioids per person year for people using in year

(MME; 95\% Cl)

2600 (2588 to 2612)
Disabled Medicare

$14.3(n=18721915 ; 14.3$ to 14.3$) \quad 25.7(n=3847676 ; 25.6$ to 25.7$) \quad 51.5(n=1128088 ; 51.3$ to 51.6$)$ $6.7(n=8596001 ; 6.6$ to 6.7$) \quad 14.4(n=8005022 ; 14.3$ to 14.4$) \quad 39.0(n=3021750 ; 38.8$ to 39.1$)$

$17(17$ to 17$) \quad 20(20$ to 20$)$

$0.6(0.6$ to 0.6$) \quad 1.5(1.5$ to 1.5$)$

$1033(1026$ to 1040$)$

$63(63$ to 64$)$

$6.2(6.2$ to 6.3$)$

9068 (8988 to 9147)

3939 (3914 to 3963)

MME=milligram morphine equivalents. Confidence intervals calculated using clustered standard errors to account for repeated observations of beneficiaries.

*Denominators are person years from table 1.

tDenominators are person quarters from table 1.

¥Average daily dose calculated as total MME of opioids filled for use in quarter divided by the number of days of insurance enrollment in the quarter. 


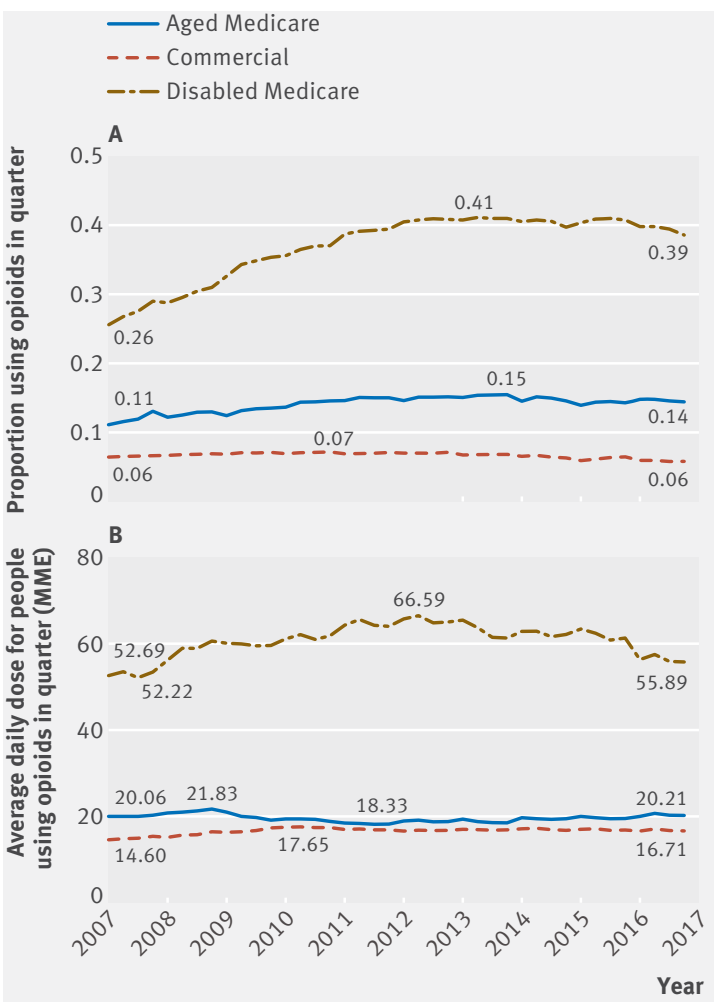

Fig 1 | Adjusted time trends in opioid use by beneficiary type, 2007-16. (A) Quarterly prevalence of opioid use; data represent predictive margins after logistic regression that included the year in which beneficiary insurance coverage started, census division, sex, and race/ethnicity. Maximum and minimum values, and values at the start and end of the study are labelled. (B) Average daily dose of opioids for people using in quarter; data represent predictive margins after negative binomial regression that included the year in which beneficiary insurance coverage started, census division, sex, and race/ethnicity. Appendix 5 gives a description of calculations; appendix 8 includes a table of predictive margins used to create the figures. $M M E=$ milligram morphine equivalents

from the low point in 2011 (18 MME) to the end of 2016 (20 MME). The average daily dose for disabled Medicare beneficiaries increased 25\% from $53 \mathrm{MME}$ at the beginning of the study to a peak level of $67 \mathrm{MME}$ in quarter 2 of 2012 and ended the study period at 56 MME.

\section{Trends by age group}

In the commercial population, children (that is, those aged 18 years and under) had a much lower prevalence of opioid use than the older age groups-1-2\% for every quarter in the study period (data underlying the graphs are provided in appendix 8). Use prevalence increased across the age groups, with the oldest commercial beneficiaries having the highest use prevalence of opioid use. Commercial beneficiaries aged 45-54 years had the highest average daily dose from quarter 1 of 2007 to quarter 4 of 2013 . From quarter 1 of 2014 , commercial beneficiaries aged 55-64 years had a similar daily dose compared to those aged 45-54 years.
In the aged Medicare category, opioid use prevalence per quarter was similar among beneficiaries aged 65 to 74 years and those aged 75 and older (fig 2A). The oldest aged Medicare beneficiaries had a lower daily dose than those aged 65 to 74 years across the entire study period. Disabled Medicare beneficiaries aged 45 to 54 years had the highest opioid use prevalence. From quarter 4 of 2011 to quarter 4 of 2013, 45\% of disabled Medicare beneficiaries aged 45 to 54 years used opioids. In both the 35-44 year and 45-54 year age groups, the average prescribed dose reached $83 \mathrm{MME}$ per day per person using opioids in quarter 2 of 2011 , and then fell to 65 and 66 MME per day, respectively, at the end of the study. Use rates of disabled Medicare beneficiaries aged 19 to 34 years were much lower than other disabled Medicare age groups.

\section{Trends in opioid used}

Appendix 9 presents trends in the opioids filled by each beneficiary population, presenting both the volume of opioids filled in MME and the number of fills. In the commercial population, by far the most commonly filled drug was hydrocodone, but in terms of volume, oxycodone and hydrocodone were similar (figures A3 and A4, appendix 9). The number of hydrocodone fills decreased substantially after 2011 in that population, while the number of oxycodone fills was relatively flat. Similar patterns were seen in the aged and disabled Medicare populations (figures A1, A2, A5, and A6; appendix 9).

We plotted the trend in concentration of opioid use over the study period, assessing the proportion of all opioids dispensed by the percentile of opioid users (by total MME filled in the year; appendix 10). In the commercial and disabled Medicare populations, use was somewhat less concentrated in the top percentiles of opioid users over time. For example, in the disabled Medicare group in 2007, the top 5\% of opioid users accounted for $49 \%$ of opioids used by that group; by 2016 , the top $5 \%$ accounted for $41 \%$ of opioids used. The aged Medicare group's use concentration changed little over the study period.

\section{Episodes of opioid use}

Long term episodes of opioid use (that is, more than 90 calendar days with at least 10 fills or at least 120 days' supply) comprised $3 \%$ of the total episodes in the commercial group, $7 \%$ in the aged Medicare group, and $14 \%$ in the disabled Medicare group (fig 3). These long term episodes accounted for the majority of the total MME; $62 \%$ of opioids dispensed to commercial beneficiaries were part of a long term episode, $70 \%$ for aged Medicare beneficiaries, and 89\% for disabled Medicare beneficiaries.

In opioid use episodes that did not meet criteria for long term use, disabled Medicare and aged Medicare beneficiaries had similar average daily observed doses, while commercial beneficiaries had higher observed doses. The three populations had substantial differences in average daily observed doses during long term episodes. The average daily observed dose 


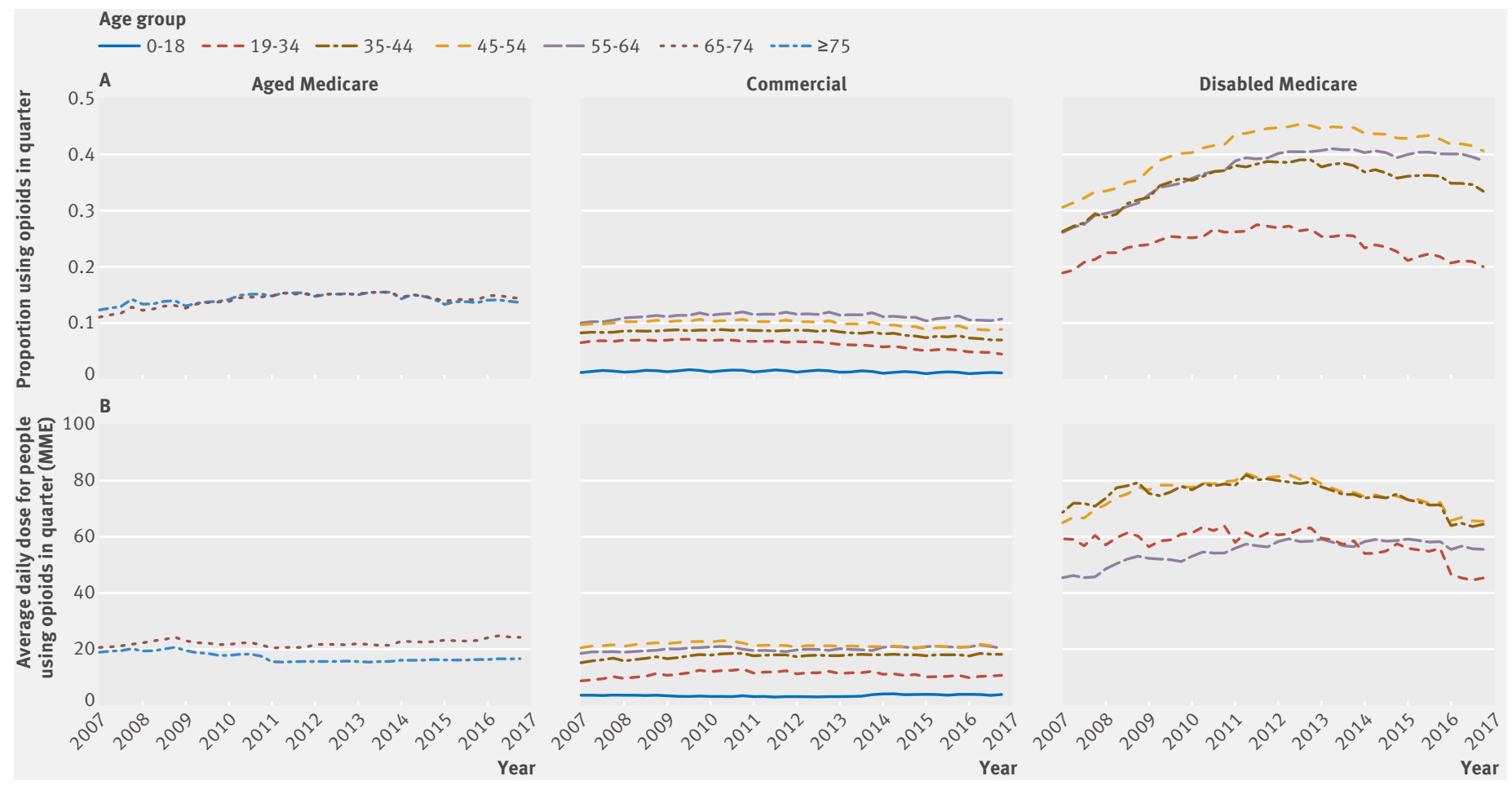

Fig 2 | Adjusted time trends in opioid use by age group, 2007-16. (A) Quarterly prevalence of opioid use; data represent predictive margins after logistic regression that included the year in which beneficiary insurance coverage started, census division, sex, and race/ethnicity. (B) Average daily dose for opioid users; data represent predictive margins after negative binomial regression that included the year in which beneficiary insurance coverage started, census division, sex, and race/ethnicity. Owing to small samples, beneficiaries with unknown age, commercial beneficiaries over age 65 years, and disabled Medicare beneficiaries under age 19 years are not shown. Appendix 8 includes a table of predictive margins used to create the figures. $M M E=$ milligram morphine equivalents

for commercial beneficiaries during long term episodes was 51 MME, 34 MME for aged Medicare beneficiaries, and 67 MME for disabled Medicare beneficiaries.

\section{Discussion}

In an analysis of opioid use in a population of commercially insured and Medicare Advantage beneficiaries from 2007 to 2016, opioid use was common, with annual use prevalence ranging from $14 \%$ among commercial beneficiaries to $52 \%$ among disabled Medicare beneficiaries. Despite a deceleration in the growing prevalence of opioid use in the middle of the period, rates of use remained at or above their 2007 level in 2016. The aged Medicare population has shown a slight increase in average daily dose for opioid users from 2011 to 2016. The bulk of opioids were dispensed as part of episodes of long term opioid use. For disabled Medicare beneficiaries, $89 \%$ of total opioids were dispensed as part of the $14 \%$ of episodes that are classified as long term. During the entire study period, the average daily observed dose for disabled Medicare beneficiaries using opioids never dropped below 50 MME per day, a level at which odds of overdose are two to four times higher than with doses of less than 20 MME per day. ${ }^{22}$ The use of opioids was high and rising through 2011 for Medicare Advantage beneficiaries. Even after an inflection point when growth in use prevalence leveled off, both prevalence and average daily dose remained at or above the 2007 levels.
The United States uses 88\% more opioids per capita than Germany, the next highest user of opioids. ${ }^{1}$ Although it is difficult to find current information on prevalence of opioid use around the world, ${ }^{23}$ one study estimated 5.9\% annual use prevalence among German adults insured by Barmer in 2009. ${ }^{24}$ Weighting our 2009 annual use prevalence to the proportion of commercial, aged Medicare, and disabled Medicare insurance beneficiaries in the US population, our equivalent figure is $21 \%$. Cross country comparisons are complicated to interpret and the adequacy of pain management has been questioned in both countries. ${ }^{25-30}$ Still, this study makes clear that opioid use rates are high in the US compared with other countries. Our data also do not show substantial decreases in use rates in response to increased focus on the epidemic.

In February 2018, the Centers for Medicare \& Medicaid Services (CMS) released a draft call letter proposing drug use review controls to be implemented by prescription drug plans serving Medicare beneficiaries through Medicare part D. ${ }^{31}$ The proposals included several measures dealing with opioid use, including a hard edit at point of sale for prescriptions totaling 90 MME (allowing seven days' supply) and a supply limit for initial opioid fills. A hard edit means that the pharmacy may not submit the prescription for payment by the insurance company until they receive notice that the insurance 


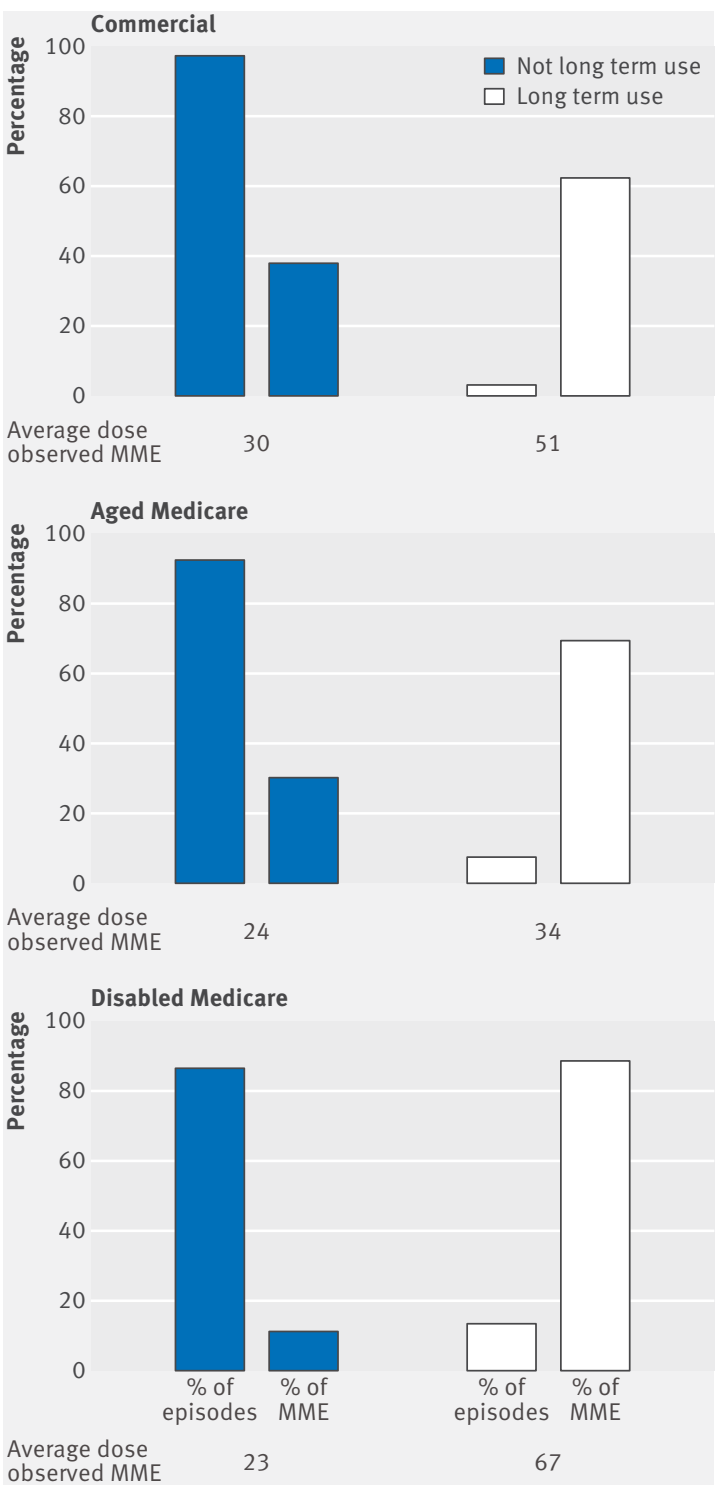

observed MME

Fig 3 | Concentration of opioids in long term use episodes. Each beneficiary population's opioid episodes and total volume of opioid use are divided into long term use (white columns) and non-long term use (blue columns); average daily MME observed during the episodes are summarized for long term use versus non-long term use. For example, in the commercial population, $3 \%$ of episodes represent chronic opioid use, which accounts for $62 \%$ of the total volume of opioid dispensed for that population (in MMEs); the average dose of opioids per day was $51 \mathrm{MME}$ in long term episodes, and 30 MME in non-long term episodes. $M M E=$ milligram morphine equivalents

company will pay for the prescription, generally after a review of medical necessity. The policy proposed in the draft call letter would allow the pharmacist to fill a seven day supply at the dose of $90 \mathrm{MME}$ or more, but the patient would need to appeal to the insurance company to get coverage of the higher dose. However, the patient would be allowed to fill the full prescription as written if the patient is willing and able to pay in cash.
Policies such as this could reduce the risk of opioid overdose for some patients, but that reduction in risk must be weighed against the burden to patients and their physicians. Because patients can buy their way out of the restrictions by paying cash, there might be equity implications to these hard edits, where patients with fewer resources might face a greater burden.

\section{Comparison of results to literature}

The observations reported here extend the findings of previous studies. For example, Guy and colleagues ${ }^{6}$ used Quintiles IMS data which captured all prescription fills, including cash paid fills, and covered a broader geographical distribution than the OLDW used in our analyses. Our study added a level of detail only possible with individual level data yielding analyses of prevalence, episodes of opioid use, and examination of subgroups to determine which groups have showed changes in opioid use. Guy and colleagues ${ }^{6}$ reported a reduction in MME dose per capita from 2010 to 2015. The Quintiles IMS data were used by Levy and colleagues $^{32}$ and Paulozzi and colleagues ${ }^{33}$ to describe opioid use in 2012. In these two studies, opioid fills per capita ranged from 0.83 to 0.92 . For a direct comparison to findings of these studies, we weighted our Medicare and commercial by the national proportion of each type of coverage in 2013 (data not shown). ${ }^{34}$ The weighted result of 0.96 opioid fills per capita was consistent with these previously reported rates and suggests that although OLDW was not a nationally representative sample, the use patterns in this population could be similar to the nation as a whole.

The annual use rates and dosages for the disabled Medicare population in our study are similar in magnitude to those reported by Morden and colleagues $^{35}$ using Medicare fee-for-service data (limited to people covered the entire year) from 2007 to 2011. In that study, the median opioid dose ranged from 9.8 to 11.0 MME. The median opioid dose per disabled Medicare beneficiary who was enrolled for the entire year ranged from 7.0 to 9.9 MME during the same period in our data (data not shown). In the Morden $^{35}$ study, the annual use rate ranged from $43.7 \%$ to $44.7 \%$, while our data for disabled Medicare beneficiaries enrolled for the entire year showed a higher annual use rate that ranged from $44.8 \%$ to $56.4 \%$ (data not shown).

Sun and Jena $^{36}$ recently reported trends in concentration of opioid use among commercially insured adults without cancer from 2001 to 2013. They found that opioid use has become more concentrated during that time in that population. In 2013, the top 5\% of opioid users accounted for 59\% of MMEs dispensed. We found a similar concentration of opioid use in a small number of users: in our study, 3\% of commercial opioid use episodes encompassed $62 \%$ of opioids filled. Our analysis adds to the findings of Sun and Jena $^{36}$ by including Medicare Advantage beneficiaries and providing more detail by distinguishing between aged and disabled Medicare beneficiaries. Stratifying the analysis this way showed substantial differences 
among the populations in the shape and patterns of opioid use over the past 10 years.

\section{Limitations of the study}

Our study sample did not capture all groups of people including uninsured people, people with fee-forservice Medicare, or people with Medicaid alone. In our sample, a proportion of beneficiaries were dually eligible for Medicare and Medicaid, but a reliable method to identify these individuals was not available, so their results were not presented separately from other Medicare beneficiaries. Because claims data were used, we were unable to include prescriptions that were not submitted to insurance either for payment or for recording amount paid toward the annual deductible. However, we expect this group of missing prescriptions to be a small proportion of total usage in an insured population, based on our similar estimate of opioids fills per capita when weighting our coverage groups for comparison with the Levy ${ }^{32}$ and Paulozzi ${ }^{33}$ studies. In a mostly commercially insured cohort, Cepeda and colleagues ${ }^{37}$ found that only $3 \%$ of opioid prescriptions filled were self paid, so the effect of these missing fills is likely minimal.

Our claims data might also have missed prescriptions filled by people with multiple sources of insurance; this effect was limited by including only those commercially insured people who were not also eligible for Medicare.

We were unable to report in this study on the prevalence of chronic pain in the population or on the proportion of people with chronic pain who received opioid treatment. Patients with chronic pain are difficult to identify by claims data, and there is currently no good algorithm to characterize chronic pain in claims data. Some analysts use ICD-9 codes 338.2x (chronic pain) and 338.4 (chronic pain syndrome), although these codes are not consistently applied and substantially underestimate the number of people with chronic pain. For example, Tian and colleagues ${ }^{38}$ have reported sensitivity of $20.3 \%$ for those codes, and they also present an algorithm to identify chronic pain (but it requires information not available in claims and was designed for use with electronic health record data rather than claims data).

Because our cohort included a population with highly variable pain duration, we did not attempt to characterize other medical care received that could shed light on the cause of the pain or other pain treatments. Future research along these lines will be important to further describe the epidemiology of pain and opioid use.

\section{Effect on practice and policy}

Although opioid use prevalence and average dose of opioids levelled off after peaks in 2012-13, all three insurance coverage groups had a higher average dose of daily MME in 2017 than in 2007. In the two Medicare beneficiary groups, prevalence of opioid use was higher in 2016 than 2007, which suggests that there may be opportunities to further optimize opioid prescribing practices to conform to guidelines. We found very high prevalence of opioid use and opioid doses in disabled Medicare beneficiaries, mostly likely reflecting the high burden of illness in this population. Doctors and patients should consider whether long term opioid use is improving the patient's ability to function, and if not, should consider other treatments either as an addition or replacement to opioid use. Evidence based approaches are needed to improve both the safety of opioid use and patient outcomes including pain management and ability to function.

This work was made possible by the Mayo Clinic Robert D and Patricia E Kern Center for the Science of Health Care Delivery.

Contributors: MMJ, HJH, MFB, EPH, and NDS conceived of and designed the work; MMJ cleaned and analyzed the data; all authors interpreted the data. MMJ, NDS, and WMH drafted the work. All authors revised the work for important intellectual content, gave final approval of the version to be published, and agree to be accountable to ensure that questions related to the accuracy or integrity of any part of the work are appropriately investigated and resolved. MMJ acts as guarantor, accepting full responsibility for the work; she had access to the data and controlled the decision to publish. The corresponding author attests that all listed authors meet authorship criteria and that no others meeting the criteria have been omitted.

Funding: This study had no external funding.

Competing interests: All authors have completed the ICMJE uniform disclosure form at www.icmje.org/coi_disclosure.pdf and declare: no support from any organization for the submitted work; no financial relationships with any organizations that might have an interest in the submitted work in the previous three years; no other relationships or activities that could appear to have influenced the submitted work

Ethical approval: This study was determined to be exempt from review by the Mayo Clinic Institutional Review Board

Data sharing: OptumLabs data are deidentified and available for research through a virtual data warehouse. OptumLabs has agreed to make the dataset for this study and the accompanying code available to researchers interested in replicating the findings through a virtual data warehouse. Interested researchers can contact the corresponding author, who will facilitate access to the data and code. The corresponding author affirms that this manuscript is an honest, accurate, and transparent account of the study being reported; that no important aspects of the study have been omitted; and that any discrepancies from the study as planned (and, if relevant, registered) have been explained.

This is an Open Access article distributed in accordance with the terms of the Creative Commons Attribution (CC BY 4.0) license, which permits others to distribute, remix, adapt and build upon this work, for commercial use, provided the original work is properly cited. See: http://creativecommons.org/licenses/by/4.0/.

1 Berterame S, Erthal J, Thomas J, et al. Use of and barriers to access to opioid analgesics: a worldwide, regional, and national study. Lancet 2016;387:1644-56. doi:10.1016/S0140-6736(16)00161-6 CDC. Drug overdose deaths in the United States continue to increase in 20152016 [updated Dec 16, 2016. http://www.cdc.gov/ drugoverdose/epidemic/index.html.

3 Davis JH. In declaration, no new funds for drug crisis. The New York Times. 10/27/2017

4 Han B, Compton WM, Jones CM, Cai R. Nonmedical prescription opioid use and use disorders among adults aged 18 through 64 years in the United States, 2003-2013. JAMA 2015;314:1468-78. doi:10.1001/jama.2015.11859

5 Rudd RA, Seth P, David F, Scholl L. Increases in drug and opioidinvolved overdose deaths - United States, 2010-2015. MMWR Morb Mortal Wkly Rep 2016;65:1445-52. doi:10.15585/mmwr. mm655051e1

6 Guy GPJr, Zhang K, Bohm MK, et al. Vital signs: changes in opioid prescribing in the United States, 2006-2015. MMWR Morb Mortal Wkly Rep 2017;66:697-704. doi:10.15585/mmwr.mm6626a4

7 Drug Enforcement Administration. ARCOS - questions \& answers [Available from: https://www.deadiversion.usdoj.gov/arcos/faq.htm. 8 Hughes A, Williams MR, Lipari RN, Bose J, Copello EAP, Kroutil LA. Prescription drug use and misuse in the United States: results from the 2015 national survey on drug use and health. 2016 [Available from: https://www.samhsa.gov/data/sites/default/files/NSDUHFFR2-2015/NSDUH-FFR2-2015.htm. 
9 Pugely AJ, Martin CT, Harwood J, Ong KL, Bozic KJ, Callaghan JJ. Database and registry research in orthopaedic surgery: part i: claimsbased data. / Bone Joint Surg Am 2015;97:1278-87. doi:10.2106/ JBJS.N.01260

10 Mues KE, Liede A, Liu J, et al. Use of the Medicare database in epidemiologic and health services research: a valuable source of real-world evidence on the older and disabled populations in the US Clin Epidemiol 2017;9:267-77. doi:10.2147/CLEP.S105613

11 Johnson SP, Chung KC, Zhong L, et al. Risk of prolonged opioid use among opioid-naïve patients following common hand surgery procedures. J Hand Surg Am 2016;41:947-957.e3. doi:10.1016/j. jhsa.2016.07.113

12 Lin LA, Bohnert ASB, Kerns RD, Clay MA, Ganoczy D, Ilgen MA. Impact of the Opioid Safety Initiative on opioid-related prescribing in veterans. Pain 2017;158:833-9. doi:10.1097/j. pain 0000000000000837

13 Reisman RM, Shenoy PJ, Atherly AJ, Flowers CR. Prescription opioid usage and abuse relationships: an evaluation of state prescription drug monitoring program efficacy. Subst Abuse 2009;3:41-51. doi:10.4137/SART.S2345

14 Weiner SG, Baker O, Rodgers AF, et al. Opioid prescriptions by specialty in Ohio, 2010-2014. Pain Med 2018;19:978-89. doi:10.1093/pm/pnx027

15 Pezalla EJ, Rosen D, Erensen JG, Haddox JD, Mayne TJ. Secular trends in opioid prescribing in the USA. J Pain Res 2017;10:383-7. doi:10.2147/JPR.S129553

16 Newhouse JP, Price M, McWilliams JM, Hsu J, McGuire TG. How much favorable selection is left in Medicare Advantage? Am J Health Econ 2015:1:1-26 doi:10.1162/AlHE a 00001

17 The Henry J. Kaiser Family Foundation. Medicare Advantage 2016 [updated 5/11/2016. http://www.kff.org/medicare/fact-sheet/ medicare-advantage/.

18 National Center for Injury Prevention and Control. CDC compilation of opioid analgesic formulations with morphine milligram equivalent conversion factors, 2015 version Atlanta, GA: Centers for Disease Control and Prevention; 2015 [Available from: http:// www.pdmpassist.org/pdf/BJA_performance_measure_aid_MME_ conversion.pdf.

19 AHFS. Propoxyphene Hydrochloride n.d. [Available from: https://www. drugs.com/monograph/propoxyphene-hydrochloride.html.

20 Von Korff M, Saunders K, Thomas Ray G, et al. De facto long-term opioid therapy for noncancer pain. Clin J Pain 2008;24:521-7. doi:10.1097/AIP0b013e318169d03b

21 StataCorp. Stata/MP: Release 15. StataCorp LLC, 2017

22 Dowell D, Haegerich TM, Chou R. CDC guideline for prescribing opioids for chronic pain - United States, 2016. MMWR Recomm Rep 2016;65:1-49. doi:10.15585/mmwr.rr6501e1

23 van Amsterdam J, van den Brink W. The misuse of prescription opioids: a threat for Europe? Curr Drug Abuse Rev 2015:8:3-14. doi: 10.2174/187447370801150611184218

24 Marschall U, L'hoest H. Opioidtherapie in der Versorgungsrealität. Ein Beitrag zur Diskussion um ein weitverbreitetes Arzneimittel. In: Repschläger U, Schulte C, Osterkamp N, eds. Gesundheitswesen aktuell 2011: Beiträge und Analysen. 2011.
25 Dietl M, Korczak D. Over-, under- and misuse of pain treatment in Germany. GMS Health Technol Assess 2011;7:Doc03.

26 Maier C, Nestler N, Richter H, et al. The quality of pain management in German hospitals. Dtsch Arztebl Int 2010;107:607-14

27 Meißner W, Komann M, Erlenwein J, Stamer U, Scherag A. The quality of postoperative pain therapy in German hospitals. Dtsch Arzteb Int 2017;114:161-7.

28 Gan TJ, Habib AS, Miller TE, White W, Apfelbaum IL. Incidence, patien satisfaction, and perceptions of post-surgical pain: results from a US national survey. Curr Med Res Opin 2014;30:149-60. doi:10.1185/ 03007995.2013 .860019

29 Geurts JW, Willems PC, Lockwood C, van Kleef M, Kleijnen J, Dirksen C. Patient expectations for management of chronic non-cancer pain: A systematic review. Health Expect 2017:20:1201-17. doi:10.1111/ hex.1252710.1111/hex.12527

30 Helfand M, Freeman MVA. Evidence-based synthesis program reports. assessment and management of acute pain in adult medical inpatients: a systematic review. Washington (DC). Department of Veterans Affairs, 2008.

31 Centers for Medicare \& Medicaid Services. Advance Notice of Methodological Changes for Calendar Year (CY) 2019 for Medicare Advantage (MA) Capitation Rates, Part C and Part D Payment Policies and 2019 draft Call Letter. 2018.

32 Levy B, Paulozzi L, Mack KA, Jones CM. Trends in opioid analgesicprescribing rates by specialty, U.S., 2007-2012. Am J Prev Med 2015:49:409-13. doi:10.1016/i.amepre.2015.02.020

33 Paulozzi LJ, Strickler GK, Kreiner PW, Koris CM, Centers for Disease Control and Prevention (CDC). Controlled substance prescribing patterns--prescription behavior surveillance system, eight states, 2013. MMWR Surveill Summ 2015;64:1-14. doi:10.15585/mmwr. ss6409a1

34 Health insurance coverage of the total population: Kaiser Family Foundation; [Available from: http://www.kff.org/other/stateindicator/total-population/?currentTimeframe $=0$ \&sortModel=\%7 B\% 22 colld\%22:\%22Location\%22,\%22sort\%22:\%22asc\%22\%7D.

35 Morden NE, Munson JC, Colla CH, et al. Prescription opioid use among disabled Medicare beneficiaries: intensity, trends, and regional variation. Med Care 2014;52:852-9. doi:10.1097/ MLR.0000000000000183

36 Sun EC, Jena AB. Distribution of prescription opioid use among privately insured adults without cancer: United States, 2001 to 2013. Ann Intern Med 2017;167:684-6. doi:10.7326/M17-1408

37 Cepeda MS, Fife D, Denarié M, Bradford D, Roy S, Yuan Y. Quantification of missing prescriptions in commercial claims databases: results of a cohort study. Pharmacoepidemiol Drug Saf 2017;26:386-92. doi:10.1002/pds.4165

38 Tian TY, Zlateva I, Anderson DR. Using electronic health records data to identify patients with chronic pain in a primary care setting J Am Med Inform Assoc 2013;20(e2):e275-80. doi:10.1136/ amiajnl-2013-001856

Web appendix: Supplementary materials 